\title{
Very long-term results (up to 17 years) with the double-orifice mitral valve repair combined with ring annuloplasty for degenerative mitral regurgitation
}

\author{
Michele De Bonis, MD, ${ }^{\mathrm{a}}$ Elisabetta Lapenna, $\mathrm{MD},{ }^{\mathrm{a}}$ Roberto Lorusso, $\mathrm{MD}, \mathrm{PhD},{ }^{\mathrm{b}}$ Nicola Buzzati, $\mathrm{MD},{ }^{\mathrm{a}}$ \\ Sandro Gelsomino, MD, PhD, ${ }^{\mathrm{c}}$ Maurizio Taramasso, $\mathrm{MD},{ }^{\mathrm{a}}$ Enrico Vizzardi, MD, ${ }^{\mathrm{d}}$ and Ottavio Alfieri, $\mathrm{MD}^{\mathrm{a}}$
}

\begin{abstract}
Objective: The very long-term results of the double-orifice mitral valve repair are unknown. The aim of this study was to assess the late clinical and echocardiographic outcomes of this technique in patients with degenerative mitral regurgitation.
\end{abstract}

\begin{abstract}
Methods: From 1993 to 2000, 174 patients with severe degenerative mitral regurgitation were treated with the double-orifice technique combined with ring annuloplasty. Mean age of patients was $52 \pm 12.8$ years, New York Heart Association class I or II was present in $71 \%$ of the patients, atrial fibrillation in $17.2 \%$, and preoperative left ventricular ejection fraction was $59.5 \% \pm 7.5 \%$. Mitral regurgitation was due to anterior leaflet prolapse in 36 patients $(20.6 \%)$, bileaflet prolapse in $128(73.5 \%)$, and posterior leaflet prolapse in 10 patients $(5.7 \%)$.
\end{abstract}

\begin{abstract}
Results: There were no hospital deaths. At hospital discharge, mitral regurgitation was absent or mild in 169 patients $(97.1 \%)$ and moderate $(2+/ 4+)$ in 5 patients $(2.8 \%)$. Mitral stenosis requiring reoperation was detected in 1 patient $(0.6 \%)$. Clinical and echocardiographic follow-up was $97.1 \%$ complete (mean length, $11.5 \pm 2.53$ years; median, 11.6 years; longest duration, 17.6 years). At 14 years, actuarial survival was $86.9 \% \pm 3.37 \%$, freedom from cardiac death was $95.8 \% \pm 1.54 \%$, and freedom from reoperation was $89.6 \pm 2.51 \%$. At the last echocardiographic examination, recurrence of mitral regurgitation $\geq 3+$ was documented in 23 patients $(23 / 169,13.6 \%)$. Freedom from mitral regurgitation $\geq 3+$ at 14 years was $83.8 \% \pm 3.39 \%$. The only predictor of recurrence of mitral regurgitation $\geq 3+$ was residual mitral regurgitation greater than mild at hospital discharge (hazard ratio, $5.7 ; 95 \%$ confidence interval, 1.6-20.6; $P=.007$ ).
\end{abstract}

Conclusions: The double-orifice repair combined with ring annuloplasty provides very satisfactory long-term results in patients with degenerative mitral regurgitation in the setting of bileaflet and anterior leaflet prolapse.

(J Thorac Cardiovasc Surg 2012;144:1019-26)

The edge-to-edge (E-to-E) technique was introduced in the surgical armamentarium of mitral valve repair during the early 1990s and has been used to treat mitral regurgitation (MR) resulting from different etiologies and mechanisms. ${ }^{1-8}$ The basic concept behind the E-to-E approach is that the competence of a regurgitant mitral valve can be restored effectively with a functional rather than an anatomic repair. Once the location of the regurgitant jet is identified accurately by transesophageal echocardiography,

\footnotetext{
From the Department of Cardiac Surgery, ${ }^{a}$ San Raffaele University Hospital, Milan, Italy; the Cardiac Surgery Unit ${ }^{\mathrm{b}}$ and the Cardiology Unit, ${ }^{\mathrm{d}}$ Community Hospital, Brescia, Italy; and the Cardiac Surgery Unit, ${ }^{c}$ Careggi Hospital, Florence, Italy. Disclosures: Authors have nothing to disclose with regard to commercial support. Read at the 92nd Annual Meeting of The American Association for Thoracic Surgery, San Francisco, California, April 28-May 2, 2012.

Received for publication March 29, 2012; revisions received June 8, 2012; accepted for publication July 25, 2012; available ahead of print Aug 27, 2012.

Address for reprints: Michele De Bonis, MD, Department of Cardiac Surgery, San Raffaele University Hospital, Via Olgettina 60, 20132 Milano, Italy (E-mail: michele.debonis@hsr.it).

0022-5223/\$36.00

Copyright (c) 2012 by The American Association for Thoracic Surgery http://dx.doi.org/10.1016/j.jtcvs.2012.07.034
}

the free edge of one leaflet is sutured to the corresponding edge of the opposing leaflet exactly in correspondence to the regurgitant jet, thereby eliminating MR. When the approximation of the free edge of the leaflets is carried out centrally, away from the commissural area, a doubleorifice mitral valve is created artificially. We have reported previously the 5-year results of the double orifice repair (DO) used for the treatment of MR resulting from different etiologies and mechanisms. ${ }^{2}$ Effectiveness and durability were very satisfactory, although suboptimal outcomes were observed in patients with rheumatic valve disease and in those who did not undergo annuloplasty. These findings and increasing clinical experience demonstrated that the main indication for the E-to-E technique is degenerative MR resulting from bileaflet prolapse (BLP) or anterior leaflet prolapse (ALP), and that a concomitant annuloplasty should be performed concomitantly to increase the durability of the repair. Therefore, we decided to assess the long-term (up to 17.5 years) clinical and echocardiographic outcomes of DO mitral valve repair adopted specifically for patients with pure degenerative, severe MR undergoing concomitant ring annuloplasty. 


$$
\begin{aligned}
& \text { Abbreviations and Acronyms } \\
& \text { ALP = anterior leaflet prolapse } \\
& \text { BLP }=\text { bileaflet prolapse } \\
& \text { DO }=\text { double orifice } \\
& \text { E-to-E }=\text { edge-to-edge } \\
& \text { IQR }=\text { interquartile range } \\
& \text { NYHA }=\text { New York Heart Association } \\
& \text { MR }=\text { mitral regurgitation } \\
& \text { PLP }=\text { posterior leaflet prolapse } \\
& \text { SAM }=\text { systolic anterior motion }
\end{aligned}
$$

\section{METHODS \\ Patients}

All consecutive patients with severe, degenerative MR treated exclusively with DO mitral repair and prosthetic ring annuloplasty at San Raffaele University Hospital of Milan (Italy) and at the Community Hospital of Brescia (Italy) from 1993 to December 2000 were enrolled in this retrospective study. In this time frame, of the 710 patients who underwent mitral repair for severe, degenerative MR, 268 (37.7\%) received a DO repair. Ninety-four patients were excluded according to one or more of the following criteria: other concomitant valve replacement procedures $(n=10)$, or DO repair performed without annuloplasty $(n=59)$ or with annuloplasty techniques other than prosthetic ring implantation, including suture annuloplasty and partial annuloplasties with strips of pericardium or Gore-Tex $(\mathrm{n}=25)$. Patients with functional tricuspid insufficiency treated with an annuloplasty and those with associated incidental coronary artery disease or atrial septal defect were retained. The final study population consisted of 174 patients $(174 / 710,24.5 \%)$. Demographic and surgical data were obtained from hospital records and reviewed. The institutional ethics committee approved this study and waived individual consent for this retrospective analysis. Preoperative characteristics of the patients are reported in Table 1. Mean age of the study population was $52 \pm 12.8$ years, New York Heart Association (NYHA) class I or II was present in $71 \%$ of the patients, atrial fibrillation was present in $17.2 \%$, and preoperative left ventricular ejection fraction was $59.5 \% \pm 7.5 \%$. MR was the result of BLP in 128 patients $(73.5 \%)$, ALP in 36 patients $(20.6 \%)$, and posterior leaflet prolapse (PLP) in 10 patients $(5.7 \%)$.

\section{Operative Technique}

All operations were carried out through a conventional median sternotomy using normothermic cardiopulmonary bypass and cold-blood cardioplegia with the exception of 4 young patients $(4 / 174,2.2 \%)$ in whom a minimally invasive approach was preferred. The mitral valve was exposed through the left atrium with the incision made in the interatrial groove. The surgical technique of DO mitral repair has been described previously., 90 Briefly, the mitral valve is inspected carefully to confirm the preoperative transesophageal echocardiographic findings. In Barlow's disease with bileaflet involvement, the entire valve is usually prolapsing, although the middle scallops of the anterior and posterior leaflets (A2 and P2) are usually the segments showing the most severe pathologic involvement. A 4-0 polypropylene stitch is passed through the mid portion of the anterior and posterior leaflets (A2 and P2), and a DO mitral valve is created. After checking that valve symmetry is respected and distortion is avoided, a continuous mattress suture is performed followed by an over-and-over continuous suture with the same 4-0 polypropylene. The length of the suture depends on the extension of the noncoapting zone of the facing leaflets. As a general rule, it should be as short as possible to avoid mitral stenosis. The distance of the suture bites from the free edges is variable, according to the redundancy of the leaflets. Typically in
Barlow's disease, it is around $1 \mathrm{~cm}$ or more to decrease the height of the myxomatous leaflets and to prevent postoperative systolic anterior motion (SAM). In the presence of prolapse/flail involving only one leaflet, the prolapsing/flailing segment has to be included in the E-to-E suture, the position of which, in this circumstance, may be somewhat asymmetric, corresponding to the center of the prolapsing/flailing portion of the leaflet. In this case, the size of the two orifices may be different, one being larger than the other one. The global mitral valve area is assessed by direct inspection and, when in doubt, by introducing Hegar dilators into the orifices. A global valve area of more than $2.5 \mathrm{~cm}^{2}$ is considered acceptable for normal-size patients. Valve competence is evaluated by forceful saline injection into the left ventricle. Last, transesophageal echo Doppler is performed routinely after weaning from cardiopulmonary bypass to assess the competence of the valve and to measure the valve area, usually by a planimetric method using the transgastric short-axis view. All patients included in this series had a concomitant annuloplasty with a semirigid or rigid prosthetic ring. The size of the ring was chosen according to the intertrigonal distance and the surface area of the anterior leaflet (mean size, $36.6 \pm 2.5 \mathrm{~mm}$ ). Twenty-six patients $(26 / 174,14.9 \%)$ required 1 or more concomitant cardiac operations, as reported in Table 1.

\section{Follow-up}

Clinical and echocardiographic follow-up information was available for 169 patients (97.1\% complete). Five patients were lost to follow-up. The mean length of follow-up was 11.5 \pm 2.53 years (range, 1.1-17.6 years) with a median of 11.6 years (interquartile range [IQR], 10.4-12.6 years). The majority of the patients were referred to us from remote geographic areas and, therefore, data were collected either through outpatient visit and transthoracic echocardiography in our institution in 55 patients $(32.5 \%)$ and by telephone contact with the patient and the referring cardiologist in 114 patients $(67.5 \%)$. For all those 114 patients, the report of at least 1 transthoracic echocardiogram performed by the referring local cardiologist within the previous 6 months was available and recorded.

\section{Statistical Analysis}

Calculations were performed using SPSS version 11.5 (SPSS Inc, Chicago, Ill) for Windows (Microsoft Corp, Redmond, Wash). Data are expressed as mean $\pm \mathrm{SD}$ or as median and IQR. For continuous, normally distributed data, comparison between 2 groups was performed with Student $t$ test for (un)paired samples as indicated. If continuous data were not distributed normally, the Mann-Whitney $U$ test or Wilcoxon's signed-rank test were used for independent or related samples, respectively. Comparison of categorical variables was performed using $\chi^{2}$ and Fisher's test. NYHA functional class and grade of MR were treated as ordinal variables and compared with Wilcoxon's signed-rank test (related samples) or with the Mann-Whitney $U$ test (independent samples). Survival and freedom from events were evaluated by Kaplan-Meier analysis. For actuarial estimates, data are presented as mean \pm standard error. Comparison among groups was performed according to the log-rank method. Univariate analysis of predictors of recurrence of MR $\geq 3+$ was performed with Cox proportional hazards regression.

\section{RESULTS \\ Mortality and Morbidity}

There were no hospital deaths. The postoperative course was rather smooth in most patients. Early and late complications are detailed in Table 2. Eighteen patients died after hospital discharge. The cause of death was cardiac related in 7 patients: 2 cases of acute myocardial infarction, 1 case of pulmonary edema, 3 cases of sudden deaths, and 1 case of aortic dissection. Actuarial survival at 14 years 
TABLE 1. Baseline characteristics of the patients and operative data

\begin{tabular}{|c|c|}
\hline No. of patients & 174 \\
\hline Age, y & $53.2 \pm 12.8$ \\
\hline Male sex, $\mathrm{n}(\%)$ & $113(64.9)$ \\
\hline \multicolumn{2}{|l|}{ NYHA class, $\mathrm{n}(\%)$} \\
\hline I & $48(27.5)$ \\
\hline II & $76(43.6)$ \\
\hline III & $50(28.7)$ \\
\hline Atrial fibrillation at presentation, $\mathrm{n}(\%)$ & $30(17.2)$ \\
\hline \multicolumn{2}{|l|}{ Mechanism of MR, n (\%) } \\
\hline Flail/prolapse of both leaflets & $128(73.5)$ \\
\hline Flail/prolapse of the anterior leaflet & $36(20.6)$ \\
\hline Flail/prolapse of the posterior leaflet & $10(5.7)$ \\
\hline Ejection fraction, $\%$ & $59 \pm 7.5$ \\
\hline \multicolumn{2}{|l|}{ Ring used for mitral annuloplasty, $\mathrm{n}(\%)$} \\
\hline Seguin St. Jude Medical & $140(80.4)$ \\
\hline Carpentier-Edwards classic & $34(19.5)$ \\
\hline Mean size of annuloplasty ring (mm) & $36.6 \pm 2.5$ \\
\hline \multicolumn{2}{|l|}{ Associated procedures, $\mathrm{n}(\%)$} \\
\hline ASD correction & $1(0.5)$ \\
\hline PFO closure & $3(1.7)$ \\
\hline CABG & $3(1.7)$ \\
\hline Tricuspid annuloplasty & $7(4)$ \\
\hline Radiofrequency ablation of AF & $12(6.8)$ \\
\hline
\end{tabular}
fibrillation.

was $86.9 \% \pm 3.37 \%$ and freedom from cardiac death was $95.8 \% \pm 1.54 \%$.

\section{Reoperation}

Seventeen patients (6 with ALP and 11 with BLP) were reoperated for significant mitral stenosis (1 patient) or severe MR (16 patients) between 1 month and 14.2 years after

TABLE 2. Postoperative and late complications

\begin{tabular}{lc}
\hline \multicolumn{1}{c}{ Complications } & $\mathbf{n}(\%)$ \\
\hline Postoperative morbidity & \\
Low-output syndrome & $5(2.8)$ \\
Prolonged ventilatory support $(>48 \mathrm{~h})$ & $4(2.3)$ \\
Reexploration for bleeding & $3(1.7)$ \\
Pericardial effusion & $3(1.7)$ \\
Pacemaker implantation & $2(1.1)$ \\
Stroke & $1(0.5)$ \\
Transischemic attack & $1(0.5)$ \\
Sternal rewiring & $1(0.5)$ \\
Late complications & \\
Acute myocardial infarction & $2(1.1)$ \\
Stroke & $2(1.1)$ \\
Congestive heart failure & $3(1.7)$ \\
Pacemaker implantation & $9(5.1)$ \\
Pericarditis & $1(0.5)$ \\
PTCA stenting for angina & $2(1.1)$ \\
Right ventricular failure & $1(0.5)$ \\
Aortic dissection & $1(0.5)$ \\
\hline PTCA, Percutaneous transluminal coronary angioplasty.
\end{tabular}

The Journal of Thoracic and Cardiovascular Surgery • Volume 144, Number 5 the initial repair (mean, $6.1 \pm 4.1$ years; median, 6.8 years). Mitral stenosis requiring reoperation was detected in $1 \mathrm{pa}-$ tient $(0.6 \%)$ with preoperative Barlow's disease and BLP who underwent mitral valve replacement about 1 month after DO repair. The atrioventricular obstruction was found to be at the subvalvular level on transesophageal echocardiography and was the result of the impingement of hypertrophic papillary muscles in the orifices of the valve. The remaining 16 patients were all reoperated because of severe MR. Three of them already had residual moderate $(2+/ 4+)$ MR at hospital discharge. Reoperations were performed in our institution for 8 patients and in other centers in the remaining 9 patients. The cause of recurrence of MR could be established in 4 patients only and was recurrent leaflet prolapse (2 patients) and anterior leaflet flail resulting from to a new chordal rupture in correspondence to the posterior orifice of the DO repair (1 patient). In the 4th patient, recurrent MR was a result of tearing of the leaflet by the E-to-E suture, associated with severe hemolysis secondary to partial prosthetic ring detachment. In the remaining 12 patients, the mechanism responsible for recurrent MR remained unclear either because reoperations were performed at other institutions or because this information was not described in detail in the operative reports. At reoperation, 16 patients had successful mitral valve replacement and 1 received a re-repair with a new E-to-E. Actuarial freedom from reoperation at 14 years was $89.6 \% \pm 2.51 \%$ (Figure 1) and was not significantly different in BLP versus $\operatorname{ALP}(90.6 \% \pm 2.96 \%$ vs $82 \% \pm 6.64 \%$ at 12 years, $P=.22)$.

\section{Echocardiographic Follow-up and Functional Status}

All patients underwent transesophageal echocardiographic control in the operating room followed by transthoracic echocardiogram at discharge. At hospital discharge, MR was absent or mild in 169 patients $(97.1 \%)$ and moderate $(2+/ 4+)$ in 5 patients $(2.8 \%)$. One hundred sixty-nine patients $(169 / 174,97.1 \%)$ had at least 1 transthoracic echocardiogram performed at the last follow-up at a mean of $10.7 \pm 3.1$ years (median, 11.2 years; IQR, 10.2-12.1 years) after mitral repair. Mitral stenosis requiring reoperation was detected in 1 patient $(0.6 \%)$. At the last follow-up, mean mitral valve area was $3.2 \pm 0.4 \mathrm{~cm}^{2}$ and MR was absent in 42 patients $(24.8 \%)$, mild in $83(49.1 \%)$, moderate in $21(12.4 \%)$, moderate to severe in $6(3.5 \%)$, and severe in 17 patients $(10 \%)$. Recurrence of MR $\geq 3+$ occurred at a median of 8.2 years (IQR, 2.8-10.7 years) after the initial repair. Freedom from MR $\geq 3+$ at 14 years was $83.8 \pm$ $3.39 \%$ (Figure 2). The mechanism of MR was not identified as a risk factor for recurrent $M R \geq 3+$. In particular, freedom from $M R \geq 3+$ was not significantly different in patients with BLP or ALP (at 12 years, $86.3 \% \pm 3.54 \%$ vs $82 \%$ $\pm 6.64 \% ; P=.54)$. The only predictor of recurrence of MR $\geq 3+$ was residual MR greater than mild at hospital discharge (hazard ratio, 5.7; 95\% confidence interval, 1.6-20.6;
PTCA, Percutaneous transluminal coronary angioplasty. 


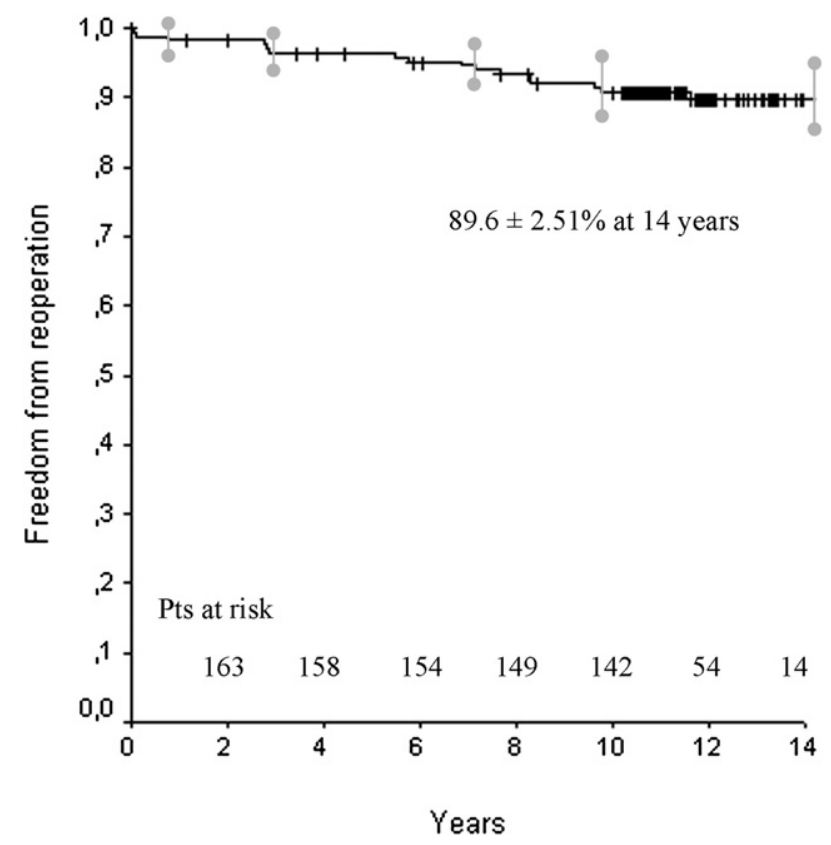

FIGURE 1. Actuarial freedom from reoperation (the standard error of the mean is shown as error bars). Pts, patients.

$P=.007)$. None of the other preoperative variables reached statistical significance; therefore, a multivariable analysis was not performed (Table 3). All patients with recurrent severe (4t/4+) MR were reoperated with the exception of 1 patient in whom severe MR developed 12 years after the initial repair and who has refused surgery so far. Freedom from the

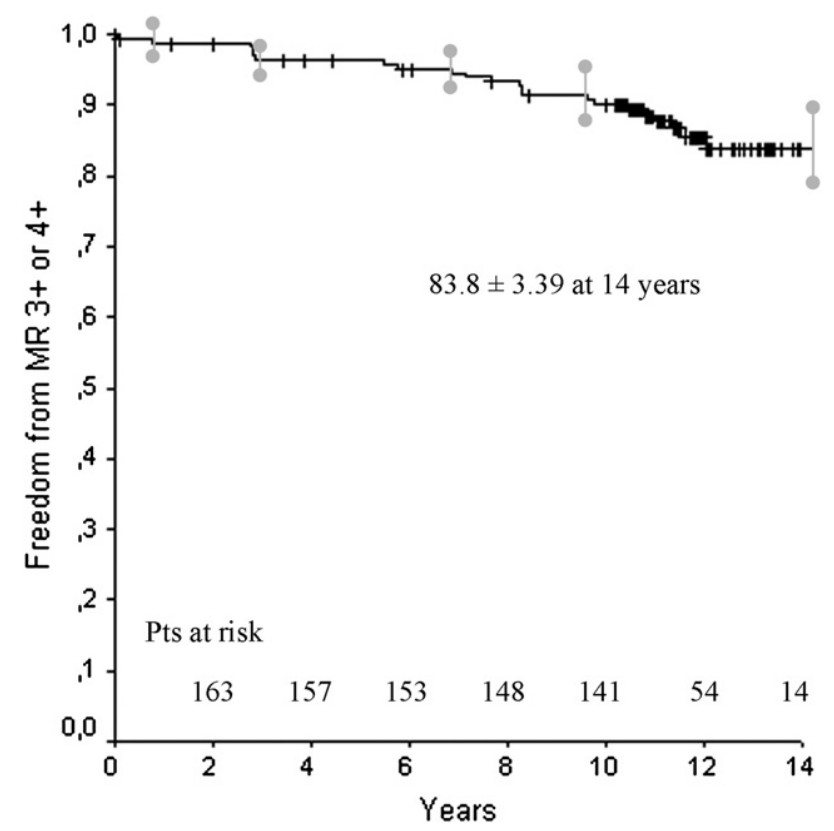

FIGURE 2. Actuarial freedom from echocardiographic recurrence of MR $\geq 3+$ (the standard error of the mean is shown as error bars). MR, Mitral regurgitation; Pts, patients.
TABLE 3. Predictors of recurrence of mitral regurgitation $\geq 3+$

\begin{tabular}{lllc}
\hline \multicolumn{1}{c}{ Predictor } & HR & $\mathbf{9 5} \% \mathbf{C I}$ & $\boldsymbol{P}$ value \\
\hline Age & 1.01 & $0.97-1.04$ & .52 \\
Male sex & 2 & $0.74-5.43$ & .16 \\
LVEF & 0.97 & $0.86-1.09$ & .68 \\
NYHA > & 0.88 & $0.32-2.41$ & .81 \\
Atrial fibrillation & 0.51 & $0.11-2.24$ & .37 \\
Bileaflet prolapse & 0.78 & $0.32-1.88$ & .58 \\
Anterior leaflet prolapse & 1.6 & $0.66-3.99$ & .28 \\
Posterior leaflet prolapse & 0.48 & $0.06-3.63$ & .47 \\
Associate procedures & 1.07 & $0.31-3.64$ & .90 \\
MR > 1+at discharge & 5.78 & $1.61-20.6$ & .007 \\
\hline$H R$, Hazard ratio; $C I$, confidence interval; $L V E F$, left ventricular ejection fraction; \\
NYHA, New York Heart Association; $M R$, mitral regurgitation.
\end{tabular}

combined end point of reoperation and $\mathrm{MR} \geq 3+$ at 14 years was $83.4 \% \pm 3.4 \%(85.6 \% \pm 3.58 \%$ for BLP and $82 \% \pm$ $6.64 \%$ for ALP, $P=.62$ ). From a functional point of view, NYHA class I was documented in 112 patients $(66.2 \%)$, NYHA class II in $49(28.9 \%)$, and NYHA class III in 8 $(4.7 \% ; P=.0001$ compared with preoperative values).

\section{DISCUSSION}

The main finding of this study is that the DO mitral valve repair combined with ring annuloplasty provides satisfactory long-term results in patients with degenerative MR in the setting of BLP and ALP. The DO technique was introduced by our group during the early 1990s essentially to treat patients with severe MR resulting from prolapse of both leaflets, prolapse of the anterior leaflet and prolapse of the posterior leaflet in the presence of an extensively calcified annulus. In addition, it was applied initially to correct MR resulting from different etiologies, including rheumatic disease. ${ }^{1,9,10}$ The 5-year results of the DO repair used in such a large variety of mechanisms and etiologies were reported previously by our group. ${ }^{2}$ Very satisfactory outcomes were observed in patients with degenerative MR undergoing DO repair combined with annuloplasty. Conversely, suboptimal results were demonstrated in patients with rheumatic valve disease and in those who did not undergo a concomitant annuloplasty. Therefore, about 20 years after its introduction, we decided to assess the longterm results of this surgical approach when it is adopted in the right setting and with the proper surgical technique-namely, in degenerative MR and with a simultaneous prosthetic ring annuloplasty. For this reason, we did not include in this study population patients with MR resulting from etiologies other than degenerative MR as well as those who underwent DO repair without annuloplasty (or with annuloplasty techniques other than a prosthetic ring implantation). Indeed, particularly at the beginning of our experience, a ring annuloplasty was mostly avoided in patients with an extensively calcified annulus. ${ }^{11}$ Similarly, partial annuloplasties with Gore-Tex or pericardial strips 
were not standard procedures and were usually combined with the DO technique in case of partial calcification of the mitral annulus, which prevented the implantation of a full prosthetic ring. Although avoiding decalcification was attractive in this setting, we have learned that this solution is often associated with suboptimal results. Nowadays, in these circumstances, we recommend mitral repair with annular decalcification followed by ring annuloplasty or mitral valve replacement rather than ringless E-to-E repair. The fact that our series, as several others reported in the literature, ${ }^{12-14}$ includes only patients with concomitant ring annuloplasty needs to be considered when we compare it with other studies also enrolling patients treated without annuloplasty. The absence of annuloplasty, indeed, has been identified as an important predictor of recurrence of MR. ${ }^{15,16}$ Most of the patients included in this study had severe degenerative MR resulting from BLP, and a minority of them had segmental prolapse of the anterior leaflet. Only 10 patients underwent DO repair for isolated PLP, and this happened at the very beginning of our experience with the E-to-E technique, usually in patients with poor preoperative conditions or with left ventricular dysfunction requiring concomitant coronary artery bypass graft, to proceed with a quick operation and have a short aortic crossclamp time. We were curious to see the very long-term outcomes of those few patients (which were actually very good) and retained them in the study population. However, besides those 10 patients, all patients with PLP have been treated in our institution with the standard quadrangular resection and its modifications (sliding plasty, folding plasty, etc). This technique has been able to provide outstanding outcomes more than 20 years after the initial repair and remains the gold standard for patients with PLP at our institution. The E-to-E approach, in this setting, has been reserved only for a few selected patients and for those with an extensively calcified annulus.

In the current study there was no hospital mortality. Late mortality, to the best of our knowledge, was unrelated to the repair technique. As in many other series of patients treated with mitral valve reconstruction, postoperative morbidity and late complications were low. Early after surgery, mitral stenosis requiring reoperation occurred in only 1 patient, and 5 more patients had a suboptimal immediate result with moderate $(2+/ 4+)$ residual MR at hospital discharge, 3 of whom required late reoperation for recurrent, severe MR. From a technical point of view, it should be emphasized that the time frame of this study includes the very beginning of our experience; therefore, the results are, at least in part, influenced by the normal learning curve that is present when any new technique is introduced. None of the patients required reoperation for postoperative SAM, demonstrating that, if the E-to-E suture is performed with deep bites to decrease the height of the leaflets, a postoperative SAM can be prevented effectively even in huge myxomatous BLP resulting from Barlow's disease. The long-term results of this study in terms of survival and freedom from cardiac death are at least comparable with those described in other series with similar follow-up periods. ${ }^{12,15-20}$ Our result of $90 \%$ freedom from reoperation at 14 years, in a population of patients affected mainly by BLP and ALP, is very satisfactory and remains within the range reported in the literature by other groups using conventional repair techniques and with a duration of follow-up ranging from 10 to 20 years. ${ }^{12,15-19,21}$ Freedom from reoperation was not significantly different in patients with BLP versus ALP. Nevertheless, patients with ALP had freedom from reoperation and from recurrence of MR $\geq 3+$ at 12 years, which was lower than that described previously by our group. ${ }^{8}$ Possible explanations for this finding are that the number of patients with ALP in this study was only 36 , representing just a minority (about one quarter) of the 133 patients included in the study published previously, and that the median follow-up of the patients with ALP in the current study was around 11 years compared with 3 years in our previous series. One strength of this study is that the long-term effectiveness and durability of the DO technique was demonstrated not only by freedom from reoperation but also by the echocardiographic controls, which were available in $97.1 \%$ of the patients. In the literature, long-term echocardiographic data in patients with BLP and ALP treated with mitral repair are reported rarely. ${ }^{15,17,20}$ Our result of $84 \%$ echocardiographic freedom from $M R \geq 3+$ at 14 years can be considered very satisfactory and at least comparable with those described in this setting by other advanced mitral valve repair centers. ${ }^{15,17,20}$ The mechanism of MR had no influence on survival, freedom from cardiac death, freedom from reoperation, and recurrence of $M R \geq 3+$. The only predictor of recurrence of $\mathrm{MR} \geq 3+$ was the presence of residual MR greater than mild at hospital discharge, confirming the importance of a perfectly competent mitral valve at the end of the reconstructive procedure. In the very few patients in whom the cause of recurrence of MR could be established, it was the result of the progression of the degenerative disease with the occurrence of new prolapsing or flailing lesions in correspondence to 1 of the 2 orifices of the E-to-E repair. Tearing of the leaflet by the E-to-E suture occurred in 1 patient only, together with prosthetic ring detachment. According to intraoperative findings, we can speculate that a too superficial stitch of the E-to-E suture was likely the cause of leaflet tearing. Last, about $70 \%$ of the patients in this series underwent mitral repair for severe MR when they were relatively asymptomatic or when they had few symptoms (NYHA I or II). Still, an important clinical improvement was documented at follow-up, with more than $95 \%$ of the patients in NYHA functional class I or class II. 


\section{Limitations}

This study has all the limitations of every retrospective data collection. In addition, the sample size is rather small, particularly with regard to patients with ALP. Moreover, because $67.5 \%$ of the patients had an echocardiographic examination performed at other institutions, we cannot exclude that the rate of recurrent MR in those patients might have been underestimated. However, this event seems rather unlikely because of the consistency between the good echocardiographic late outcomes reported and the very satisfactory clinical conditions described by the patients. In addition, no consistent data were available in terms of left ventricular dimensions, right ventricular function, and systolic pulmonary artery pressure at follow-up, and therefore they could not be analyzed and compared with preoperative values. Another limitation of this study is represented by the fact that the causes of recurrent MR remain unknown in most patients either because they were reoperated at other institutions or because this information could not be retrieved from the operative reports. Last, as we emphasized earlier, this study includes a selected group of patients, and this needs to be taken into account when looking at the late outcomes of this technique. Only patients with degenerative MR resulting primarily from BLP or ALP treated with a DO repair combined with ring annuloplasty were included. The results reported in this series, therefore, cannot be extended to patients submitted to DO technique without concomitant annuloplasty and to cases of MR resulting from etiologies other than degenerative.

\section{CONCLUSION}

In conclusion, our clinical and echocardiographic data confirm that the DO mitral valve repair, combined with ring annuloplasty, provides very satisfactory long-term results in patients with degenerative MR in the setting of BLP and ALP.

\section{References}

1. Fucci C, Sandrelli L, Pardini A, Torracca L, Ferrari M, Alfieri O. Improved results with mitral valve repair using new surgical techniques. Eur J Cardiothorac Surg. 1995;9:621-6.

2. Alfieri O, Maisano F, De Bonis M, Stefano PL, Torracca L, Oppizzi M, et al. The double-orifice technique in mitral valve repair: a simple solution for complex problems. J Thorac Cardiovasc Surg. 2001;122:674-81.

3. Kuduvalli M, Ghotkar SV, Grayson AD, Fabri BM. Edge-to-edge technique for mitral valve repair: medium-term results with echocardiographic follow-up. Ann Thorac Surg. 2006;82:1356-61.

4. Brinster DR, Unic D, D'Ambra MN, Nathan N, Cohn LH. Midterm results of the edge-to-edge technique for complex mitral valve repair. Ann Thorac Surg. 2006; 81:1612-7.

5. Bhudia SK, McCarthy PM, Smedira NG, Lam BK, Rajeswaran J, Blackstone EH. Edge-to-edge (Alfieri) mitral repair: results in diverse clinical settings. Ann Thorac Surg. 2004;77:1598-606.

6. Kherani AR, Cheema FH, Casher J, Fal JM, Mutrie CJ, Chen JM, et al. Edge-toedge mitral valve repair: the Columbia Presbyterian experience. Ann Thorac Surg. 2004;78:73-6.

7. De Bonis M, Lapenna E, La Canna G, Ficarra E, Magliaro M, Torracca L, et al. Mitral valve repair for functional mitral regurgitation in end-stage dilated cardiomyopathy: the role of the "edge-to-edge" technique. Circulation. 2005;112:I402-8.
8. De Bonis M, Lorusso R, Lapenna E, Kassem S, De Cicco G, Torracca L, et al. Similar long-term results of mitral valve repair for anterior compared with posterior leaflet prolapse. J Thorac Cardiovasc Surg. 2006;131:364-8.

9. Maisano F, Torracca L, Oppizzi M, Stefano PL, D'Addario G, La Canna G, et al. The edge-to-edge technique: a simplified method to correct mitral insufficiency. Eur J Cardiothorac Surg. 1998;13:240-5.

10. Maisano F, Schreuder JJ, Oppizzi M, Fiorani B, Fino C, Alfieri O. The doubleorifice technique as a standardized approach to treat mitral regurgitation due to severe myxomatous disease: surgical technique. Eur J Cardiothorac Surg. 2000; 17:201-5.

11. Maisano F, Caldarola A, Blasio A, De Bonis M, La Canna G, Alfieri O. Midterm results of edge-to-edge mitral valve repair without annuloplasty. J Thorac Cardiovasc Surg. 2003;126:1987-97.

12. Braunberger E, Deloche A, Berrei A, Abdallah F, Celestin JA, Meimoun P, et al. Very long-term results (more than 20 years) of valve repair with Carpentier's techniques in nonrheumatic mitral valve insufficiency. Circulation. 2001;104: I8-11.

13. Jouan J, Berrebi A, Chauvaud S, Menasché P, Carpentier A, Fabiani JN. Mitral valve reconstruction in Barlow disease: long-term echographic results and implications for surgical management. J Thorac Cardiovasc Surg. 2012;143:S17-20.

14. Chan V, Ruel M, Chaudry S, Lambert S, Mesana TG. Clinical and echocardiographic outcomes after repair of mitral valve bileaflet prolapse due to mixomatous disease. J Thorac Cardiovasc Surg. 2012;143:S8-11.

15. Gillinov AM, Blackstone EH, Alaulaqi A, Sabik JF 3rd, Mihaljevic T, Svensson LG, et al. Outcomes after repair of the anterior mitral leaflet for degenerative disease. Ann Thorac Surg. 2008;86:708-17.

16. Flameng W, Meuris B, Herijgers P, Herregods MC. Durability of mitral valve repair in Barlow disease versus fibroelastic deficiency. J Thorac Cardiovasc Surg. 2008; 135:274-82.

17. David TE, Ivanov J, Armstrong S, Christie D, Rakowski H. A comparison of outcomes of mitral valve repair for degenerative disease with posterior, anterior, and bileaflet prolapse. J Thorac Cardiovasc Surg. 2005;130:1242-9.

18. DiBardino DJ, El Bardissi AW, McClure RS, Razo-Vasquez OA, Kelly NE, Cohn LH. Four decades of experience with mitral valve repair: analysis of differential indications, technical evolution, and long-term outcome. J Thorac Cardiovasc Surg. 2010;139:76-83.

19. Salvador L, Mirone S, Bianchini R, Regesta T, Patelli F, Minniti G, et al. A 20year experience with mitral valve repair with artificial chordae in 608 patients. $J$ Thorac Cardiovasc Surg. 2008;135:1280-7.

20. Okada Y, Nasu M, Koyama T, Shomura Y, Yuzaki M, Murashita T, et al. Outcomes of mitral valve repair for bileaflet prolapse. J Thorac Cardiovasc Surg. 2012;143:S21-3.

21. Mohty D, Orszulak TA, Schaff HV, Avierinos JF, Tajik JA, Enriquez-Sarano M. Very long-term survival and durability of mitral valve repair for mitral valve prolapse. Circulation. 2001;104:I1-7.

\section{Discussion}

Dr Donald D. Glower (Durham, NC). You have just heard De Bonis and colleagues present what is probably one of the world's longest and largest series of edge-to-edge or double-orifice repairs for mitral valve prolapse. This series is important in documenting the results that can be achieved in selected patients using yet another potentially powerful tool for mitral valve repair.

Personally, it took me several attempts to get the feel for this technique, but over the past 6 years I found the technique to be useful, even in repairing most cases of posterior leaflet prolapse, without leaflet resection. I feel that the edge-to-edge repair may minimize the potential for SAM in large myxomatous valves repaired without leaflet resection where even a $40-\mathrm{mm}$ ring may be too small in some of those patients, and the edge-to-edge repair may add an additional safety factor in ensuring good long-term leaflet coaptation, particularly in patients with complex myxomatous valves. I have 3 questions for you.

Could you clarify, based on your experience to date and if we limit ourselves to patients with prolapse only, what would you 
say might be potential indications and contraindications for using the edge-to-edge or double-orifice technique?

Dr De Bonis. Sorry, I can't really hear you. Contraindications?

Dr Glower. I think you have talked about in the past that you would not use this in rings less than $30 \mathrm{~mm}$. Is there anything you would see about a patient that would cause you not to use this technique?

Dr De Bonis. I would say that one contraindication is annular calcification. We excluded those patients from this series. At the beginning, we thought that the edge-to-edge technique could be a very good solution in patients with a heavily calcified annulus-a simple technique, a suture between the 2 leaflets that we hoped could be long-lasting. That is not true. So one contraindication is annular calcification. We would now decalcify the annulus and use this or other techniques after decalcification or replace the valve.

Another contraindication is the presence, of course, of a small annulus. If you have to put in a small ring, then the risk of stenosis increases, but this is seen in a relatively small number of patients. If you ask me which ring we have been using, we have been using in the degenerative setting semirigid, complete rings from 30 up to 40. Most of the patients have got the ring 36 or 38 , but there is a limited number of patients with No. 30 rings. In those patients, the residual mitral valve area is borderline, which means between $2 \mathrm{~cm}^{2}$ and 2.5 $\mathrm{cm}^{2}$, but we had no major problems in terms of mitral stenosis.

Dr Glower. The data you have presented were patients all operated more than 10 years ago, up to the year 2000 . Have you changed your technique since the year 2000 or your selection criteria?

Dr De Bonis. There have been some changes. In terms of rings, for instance, we are not using anymore a complete ring. We are using almost exclusively a partial posterior band from trigone to trigone. I don't think this is really going to make a major difference in terms of long-term results. We didn't find any difference between the complete ring or the partial ring. So that is one modification we did. Moreover, we have been using the edge-to-edge technique in a less aggressive way than we were doing before. We are not using this technique anymore in rheumatic disease, and we have been using artificial chordae or conventional reconstructions also for Barlow's disease.

But still, this is a technique which is in our armamentarium and we use it anytime we think it can be particularly useful-for instance, when you need a quick operation, when you have to do multiple procedures, in case of a particularly complex repair, or when you have opposite lesions on facing segments of the anterior and posterior leaflets. Those are a relatively small number of patients, but they do exist. For instance, you can have an important prolapse of the anterior leaflet combined with hypoplasia or tethering of the posterior one resulting from dilatation of the left ventricle. Those types of opposing lesions can be very well addressed by the edge-to-edge technique.

Dr Glower. You mentioned that you started out applying the technique even to patients with posterior leaflet prolapse but have backed off of that. Do you think there is a role for this?

Dr De Bonis. That is a very interesting question. I would like to emphasize that this is a very early series of patients. So, of course, there is a lot of learning curve. But as it has been reported in the slides and in the paper, 10 patients had isolated posterior leaflet prolapse. Nowadays we would not use the edge-to-edge technique for isolated prolapse of the posterior leaflet. We use conventional techniques, folding, sliding, whatever. The results at long term of the classical Carpentier techniques in this setting are extremely good.

But what is interesting is that none of the patients with posterior leaflet prolapse reported in this series have been reoperated or did have recurrent MR. Among those patients, 1 died, not from a valve-related cause, but the other 9 patients have a perfectly competent valve.

So the question is: Does it work? I think so; I think it does work. Do you have to use it? We don't, but it is up to the surgeon. And I don't see a specific contraindication to use it.

Dr Glower. Thank you. Excellent paper.

Dr Walaa A. Saber (Cairo, Egypt). Can you tell us, please, if in all your patients the edge-to-edge repair was central? In other words, the double orifice is always equal or sometimes you have unequal orifices?

Dr De Bonis. Thank you very much for your question. I would like to emphasize that this series includes just patients with doubleorifice mitral valve repair. So this series is just a series of patients with central edge-to-edge stitch. Those with commissural edge-toedge have been excluded. We have reported them and published. We have had very good results with the commissural edge-toedge technique. In that specific setting, which is commissural prolapse, the edge-to-edge technique remains the first choice in our hands, and the results are really very good.

When you perform a central edge-to-edge technique, you have to keep in mind that your suture has to address the lesions, which means that if you have the flail that is between A1 and A2, it is not necessary to put the stitches in the central portion of A2, because you don't want to leave the flailing segment that is closer to A1. So your suture must be asymmetric; otherwise, you will not get a competent valve. So you can end up with orifices that are of different sizes, but this doesn't matter, because computational models have shown that the valve is going to behave as a valve that has an area that is the sum of the 2 orifices. So it doesn't matter if one orifice is $2 \mathrm{~cm}^{2}$ and the other one is $1 \mathrm{~cm}^{2}$ or they are both $2 \mathrm{~cm}^{2}$.

Did I answer your question?

Dr Saber. Yes. Thank you.

Dr Robert A. Dion (Genk, Belgium). Congratulations, Michele, for a very nice presentation. I just have 2 small questions. First, did you ever do a stress test to measure the gradient at exercise? Second question: How do you decide that a ring is too small for these particular patients?

Dr De Bonis. Thank you very much, Dr Dion. Indeed, I did not show that for time reasons and also because that is not part of this study, but 30 of those patients, exactly those patients, with ring and edge-to-edge repair, were submitted to exercise echocardiography. This paper has been published in the Journal of Heart Valve Disease in 2002, first name is Dr Agricola, and there we addressed your question.

So we put the patients on the bicycle, we did an exercise test, and the mean area at baseline was $3.2 \mathrm{~cm}^{2}$. During exercise it became, at the peak of the exercise, $4.3 \mathrm{~cm}^{2}$. In terms of gradient, the mean gradient at baseline was $2.8 \mathrm{~mm} \mathrm{Hg}$ and it increased to 4.6 $\mathrm{mm} \mathrm{Hg}$. We never found pulmonary hypertension, so we excluded the possibility of stenosis.

Addressing your second question, when you decide the ring is too small, that is very important. It is really a matter of experience. Just by looking at the 2 orifices with the forceps when you have 
made your central stitch, you can already somehow feel if they are too small. In addition, it is even easier if you just put a Hegar inside. So if I am putting a 30-mm ring, I start to be concerned, but, in case of doubt, I can always measure the size of the orifices. For instance, if I can put in a Hegar which is No. 20, there is no risk of stenosis at all.

Access to The Journal of Thoracic and Cardiovascular Surgery Online is reserved for print subscribers!

Full-text access to The Journal of Thoracic and Cardiovascular Surgery Online is available for all print subscribers. To activate your individual online subscription, please visit The Journal of Thoracic and Cardiovascular Surgery Online, point your browser to http://www.mosby.com/jtcvs, follow the prompts to activate your online access, and follow the instructions. To activate your account, you will need your subscriber account number, which you can find on your mailing label (note: the number of digits in your subscriber account number varies from 6 to 10). See the example below in which the subscriber account number has been circled:

\section{Sample mailing label}

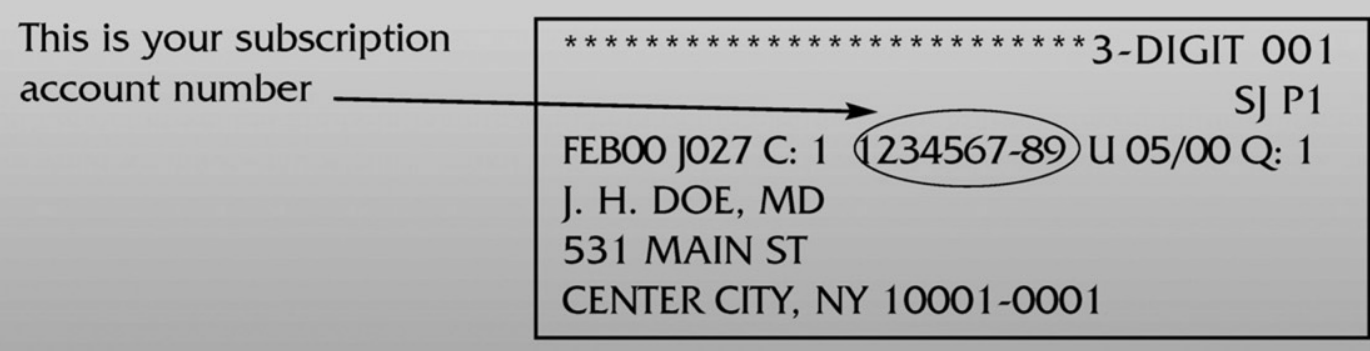

Personal subscriptions to The Journal of Thoracic and Cardiovascular Surgery Online are for individual use only and may not be transferred. Use of The Journal of Thoracic and Cardiovascular Surgery Online is subject to agreement to the terms and conditions as indicated online. 